\title{
Ionic liquids as phase transfer catalysts: Enhancing the biphasic extractive epoxidation reaction for the selective synthesis of $\beta$-O-glycosides
}

\author{
Cintia C. Santiago, Leticia Lafuente, Rodolfo Bravo, Gisela Díaz, Agustín Ponzinibbio* \\ Laboratorio de Estudio de Compuestos Orgánicos (LADECOR), Departamento de Química, Facultad de Ciencias Exactas, Universidad Nacional de La Plata, \\ 47 y 115, 1900 La Plata, Argentina
}

\section{A R T I C L E I N F O}

\section{Article history:}

Received 12 July 2017

Revised 11 August 2017

Accepted 13 August 2017

Available online 14 August 2017

Keywords:

Ionic liquids

Phase transfer catalysis

$\beta$-O-glycosides

Oxone

Epoxidation

\begin{abstract}
A B S T R A C T
Ionic liquids promoted the direct epoxidation of glycals acting as PTC. 1,2-anhydrosugars were prepared by the oxidation of glycals under biphasic conditions with dimethydioxirane generated in situ from oxone/acetone and amphiphilic IL's as catalysts. $\beta$-O-glycosides were synthesized in good yields by the nucleophilic ring opening of epoxy carbohydrate derivatives. Also, 3,4,6-benzyl protected carbohydrates and $\beta-\mathrm{N}$-glycosides could be prepare by this method.
\end{abstract}

๑) 2017 Elsevier Ltd. All rights reserved.
Epoxides are important organic intermediates due to their high reactivity. The nucleophilic ring opening reaction takes place with high stereocontrol leading selectively to pure products. ${ }^{1-3}$ Commonly, the oxidation of alkenes to afford epoxides was achieved with organic peracids and peroxy acids, but lately dioxiranes have been used as new oxidizing agents.

Dimethyldioxirane (DMDO) is commercially available in low concentration and unstable solutions, nevertheless it can be prepared in situ by the oxidation of acetone with oxone. ${ }^{4-6}$ The complete epoxidation methodology often requires an efficient interchange of species between the organic phase where main substrates are dissolved and the aqueous media. Phase transfer catalysts (PTC) become irreplaceable reactants for the occurrence of biphasic reactions. Ionic liquids can be designed and synthesized on demand incorporating different active moieties. Molecules with amphiphilic structures are often used in organic synthesis to facilitate reactions between organic reactants and ionic inorganic salts, recently some IL's were tested as PTC. ${ }^{7-10}$

In the last years, there has been sustained interest in the selective synthesis of $\beta$-glycosides. The synthesis of 1,2 -anhydrosugars and the subsequent nucleophilic ring opening reaction is a promising methodology to achieve this desired carbohydrate derivatives.

\footnotetext{
* Corresponding author.

E-mail address: ponzinibbio@quimica.unlp.edu.ar (A. Ponzinibbio).
}

Despite some techniques were developed and many synthetic efforts were made, there is still a demand for green methods in the selective synthesis of 2-hydroxy-glycosides. ${ }^{11-13}$

For several years, we have been interested in the synthesis of carbohydrate derivatives. In our laboratory, different methods were applied to the synthesis of $\mathrm{C}$-, $\mathrm{O}$ - and $\mathrm{N}$-glycosides with promising biological activity as antiproliferative agents or enzymatic inhibitors. ${ }^{14}$ In view of our ongoing efforts to develop new environmentally friendly catalytic processes, we decided to investigate the use of ionic liquids as phase transfer catalyst for biphasic synthesis of 1,2-anhydrosugars and 2-hydroxy-glycosides.

As previously stated, eco-friendly ionic liquids as promoters and catalyst represent an interesting alternative in organic synthesis developments. To study in detail the use of ILs in epoxidation reactions, we tested a series of ILs with alkyl substituents on the quaternary cation. The ILs were prepared with excellent yields using a one-pot solventless methodology. ${ }^{15}$

At first, we studied the cyclohexene oxidation in different ways to optimize the reaction conditions. The method includes a ketone -acetone-, and a peracid -potassium peroxymonosulphate $\left(\mathrm{KHSO}_{5}\right)$ - commercially available as Oxone $\left(2 \mathrm{KHSO}_{5} \cdot \mathrm{KHSO}_{4} \cdot \mathrm{K}_{2} \mathrm{SO}_{4}\right)$. The well known mechanism indicates that $\mathrm{KHSO}_{5}$ is the oxidizing agent and acetone acts as catalyst. ${ }^{4}$ Despite many applications have been reported, major problems are, low conversions and yields of the corresponding dioxirane and their subsequent alkene oxidation. To compile accurate information, we divided the 
preliminary experiments in three different systems: 1) epoxidation with $\mathrm{KHSO}_{5}$ and acetone in aqueous media, 2) epoxidation with $\mathrm{KHSO}_{5}$, acetone and biphasic media (water/dichloromethane), 3) epoxidation with $\mathrm{KHSO}_{5}$, acetone, biphasic media and a IL as a phase transfer catalyst (1-butyl-3-methylimidazolium tetrafluoroborate, $\mathrm{BMImBF}_{4}$ ).

By comparing the results obtained, it could be concluded that the use of PTC is essential to enhance the reaction performance. In system $1, \mathrm{KHSO}_{5}$ was used as an aqueous solution, dimethyldioxirane (DMDO) produced from acetone and the peracid in the basic aqueous phase reacts with cyclohexene in the organic media and at the interface of cyclohexene/ $\mathrm{KHSO}_{5}$. When a solvent is added to the system (case 2), acetone can be dissolved in both aqueous and dichloromethane phases, for this reason DMDO can be formed in the aqueous solution and in the interface. The presence of $\mathrm{CH}_{2} \mathrm{Cl}_{2}$ facilitates the migration of DMDO to the organic phase where cyclohexene was oxidized, so the yields are higher. It's a typical extractive reaction process. Finally, system 3 is also an extractive process but with better efficiency. The DMDO could be formed and transfer to the organic phase easily and faster. The peracid forms a salt with the organic cation of PTC. This salt moves to the dichloromethane phase and oxidized the acetone to produce the desired DMDO (Fig. 1).

Then we screened imidazolium ILs with different alkyl substitutes and anions. As expected ILs with $\mathrm{BF}_{4}^{-}$anion acts more efficiently in the interchange of peracid $\left(-\mathrm{HSO}_{5}\right)$ between the phases. It's well known that ILs with $\mathrm{PF}_{6}^{-}$anions are barely soluble in water, therefore their capacity to transfer ions from the aqueous to the organic phase is lower. Increasing the length of the $\mathrm{N}$-alkyl substituent in the imidazolium cation represents an improvement in the amphiphilic character of the molecule. Therefore, 1-dodecyl3-methylimidazolium tetrafluoroborate $\left(\right.$ DodMImBF$\left._{4}\right)$ represents the best choice to enhance the formation and reactivity of DMDO in the dichloromethane phase.

Considering the promising results obtained we tried to extrapolate this methodology to the biphasic epoxidation of endo-glycals since the nucleophilic ring opening of the 1,2-anhydrosugars leads to biologically relevant $\beta$-glycosides.Table 1

Thus, we performed and analyzed the model tandem reaction of biphasic oxidation of 3,4,6-tri-O-benzyl-D-glucal with DMDO, gen-

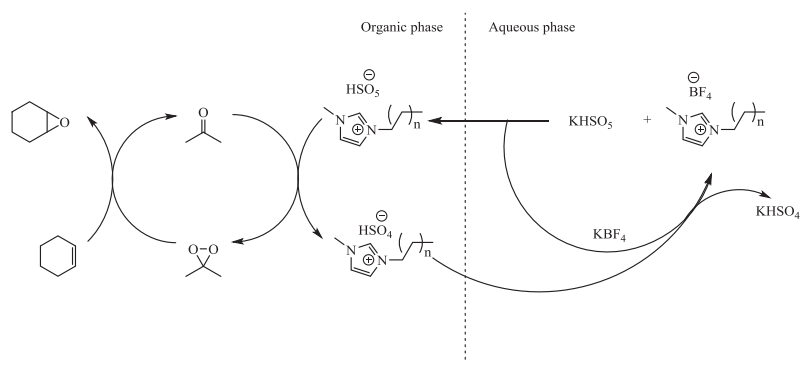

Fig. 1. Oxidation of cyclohexene by DMDO in biphasic media.

Table 1

Epoxidation of cyclohexene in three different media.

\begin{tabular}{ll}
\hline System & \% Conversion \\
\hline 1 & 50 \\
2 & 69 \\
3 & 91
\end{tabular}

Table 2

Epoxidation of TOBnGlu using different IL as PTC.

\begin{tabular}{llll}
\hline Entry & PTC & Time of epoxidation step (h) & Yield (\%) \\
\hline 1 & BMImBF $_{4}$ & 12 & $5 \%$ \\
2 & BMImPF $_{6}$ & 12 & $5 \%$ \\
3 & $\mathrm{HMImBF}_{4}$ & 12 & $40 \%$ \\
4 & $\mathrm{HMImPF}_{6}$ & 12 & $10 \%$ \\
5 & DodMImBF$_{4}$ & 3 & $70 \%$ \\
6 & DodMImPF $_{6}$ & 12 & $15 \%$ \\
\hline
\end{tabular}

erated in situ, using several ILs as PTC, and the subsequent $\mathrm{MeOH}$ addition to generate more sTable 2-hydroxy-OMe- glycosides. The experiments to test the efficiency of ILs as PTC are shown in Table 2.

Room temperature, slightly basic aqueous solution, dichloromethane, intense magnetic stirring $(700 \mathrm{rpm})$ and IL as PTC to accelerate the exchange of reactive species between phases conforms the method proposed as described in detail in the experimental section. Very good yields and high $\beta$ selective products were obtained, after column chromatography purification, as confirmed by NMR analysis. ${ }^{16}$

With the method optimized a variety of nucleophilic alcohols were tested for the scope and specificity of the system (Table 3 ). With less hindered alcohols the yields were better than ones bearing a secondary or tertiary -OH group. Comparing the substrate influence, glycals derived from D-glucose and D-galactose were tested, the yields obtained were similar, regardless of the C4 configuration.

In all cases, excellent to very good yields were obtained. The anomeric selectivity was studied by the analysis of ${ }^{1} \mathrm{H}$ NMR spectra. As expected, due to the anti nucleophilic opening of the $\alpha$-epoxide generated by oxidation of TOBnGlu by DMDO, all $\beta$ - configuration products were obtained, deducted by the chemical shifts and coupling constants of the anomeric proton.

During preliminary studies, it was detected in some cases that 1,2 diols were obtained, presumably due to the nucleophilic attack of $\mathrm{H}_{2} \mathrm{O}$ after the oxidation reaction. Especially for non-imidazolium IL's such as $\mathrm{BPyBF}_{4}$ and trihexyl(tetradecyl)phosphonium dicyanamide (Cyphos 105). An endeavor to expand the scope was done to synthesize sugar derived 1,2 diols. Carbohydrate derivatives with selective protection of their multiple - $\mathrm{OH}$ groups are useful intermediates in glycoside synthetic chemistry. ${ }^{17}$ As seen in Table 4, $\mathrm{BuPyBF}_{4}$ and Cyphos 105 are effective catalyst for the transformation of protected glycals into their corresponded 1,2 diols in moderate yields. NMR analysis indicates that the stereochemistry at C2 is equatorial in every case, nevertheless anomeric mixtures of the diols were obtained (anomeric ratio $\alpha / \beta$ 1.5:1 in all cases). ${ }^{18}$

Finally, we studied the selectivity towards different nucleophilic moieties in the reagents. An interesting result was achieved when ethanolamine was used as nucleophile. A $\beta$-N-glycoside was obtained after $6 \mathrm{~h}$ through a regio- and stereoselective ring opening reaction in good yields and enantiopure form (Fig. 2).

The complete analysis by ${ }^{1} \mathrm{H},{ }^{13} \mathrm{C}$ NMR and gHSQC, gCOSY and NOESY experiments confirm the selectivity of the product formed. ${ }^{19}$

In summary, the use of amphiphilic IL's as PTC in the oxidation of benzyl protected glycals conforms a simple, rapid and efficient method to the synthesis of $\beta$-O-2-hydroxyglycosides, current building blocks of biologically active molecules. Moreover, under certain reaction conditions 1,2 unprotected carbohydrates could be prepared. Further work expanding on the scope of the substrates and on the suitability of the protocol to prepare $\beta$-N-glycosides are under way in our laboratory. 
Table 3

Reactions of 1,2-anhydro-3,4,6-tri-O-benzyl- $\beta$-D-glucopyranoside with several nucleophiles. ${ }^{\mathrm{a}}$

\begin{tabular}{|c|c|c|c|c|}
\hline Entry & Glycal & Alcohol & Product & Yield $(\%)^{b}$ \\
\hline 1 & $\mathrm{nO}^{-1}$ & $\mathrm{MeOH}$ & ne & 70 \\
\hline 2 & & EtOH & & 75 \\
\hline 3 & & iPrOH & $\mathrm{BnO}$ & 64 \\
\hline 4 & & $\mathrm{BnOH}$ & & 60 \\
\hline 5 & DIV & $\mathrm{MeOH}$ & Di & 77 \\
\hline 6 & & EtOH & & 73 \\
\hline 7 & & iPrOH & $\mathrm{BnO}$ & 65 \\
\hline 8 & & $\mathrm{BnOH}$ & & 60 \\
\hline
\end{tabular}

${ }^{a}$ Reagents and conditions: i) Oxone (2 equiv.), acetone, DodMImBF 4 (0.1 equiv.), $\mathrm{NaHCO}_{3}, \mathrm{H}_{2} \mathrm{O}, \mathrm{CH}_{2} \mathrm{Cl}_{2}$ ii) $\mathrm{Alcohol}$, rt.

b Yields calculated after purification by column chromatography.

Table 4

Synthesis of 1,2 diols from glycals via DMDO oxidation. ${ }^{a}$

\begin{tabular}{|c|c|c|c|c|}
\hline Entry & Glycal & IL & Product & Yield $(\%)^{\mathrm{b}}$ \\
\hline 1 & $\mathrm{BnO}^{-}$ & BuPyBF4 & & 70 \\
\hline 2 & & Cyphos 105 & & 75 \\
\hline 3 & & BuPyBF4 & $n c$ & 77 \\
\hline 4 & & Cyphos 105 & $\mathrm{BnO}^{-}$ & 45 \\
\hline
\end{tabular}

${ }^{a}$ Reagents and conditions: i) Oxone (2 equiv.), acetone, IL (0.1 equiv.), $\mathrm{NaHCO}_{3}, \mathrm{H}_{2} \mathrm{O}, \mathrm{CH}_{2} \mathrm{Cl}_{2} 0^{\circ} \mathrm{C}$ to rt.

b Yields calculated after purification by column chromatography.

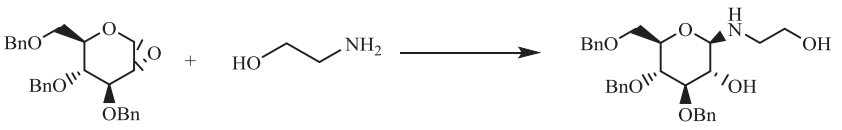

Fig. 2. Nucleophilic attack of 1,2-anhydroglycal with ethanolamine.

\section{Acknowledgments}

Authors wish to thank Comisión de Investigaciones Científicas de la Provincia de Buenos Aires (CICPBA), UNLP and CONICET for their financial support to the present work. 


\section{References}

1. Cerny M. In: Baker DC, Horton D, eds. Advances in carbohydrate chemistry and biochemistry, vol. 58. London: Academic Press; 2003:121-198.

2. Halcomb RL, Danishefsky SJ. J Am Chem Soc. 1989;111:6661-6666.

3. Liu KKC, Danishefsky SJ. J Org Chem. 1994;59:1895-1897.

4. O'Connell A, Smyth T, Benjamin K. Catal Today. 1996;32:273-278.

5. Kachasakul P, Assabumrungrat S, Praserthdam P, Pancharoen U. Chem Eng J. 2003;92:131-139.

6. Alavi Nikje MM, Mozaffari Z. Des Mon Polym. 2007;10:67-77.

7. Muthusamy S, Gnanaprakasam B. Tetrahedron Lett. 2005;46:635-638.

8. Okamoto S, Takano K, Ishikawa T, Ishigami S, Tsuhako A. Tetrahedron Lett. 2006; 47:8055-8058.

9. Cokoja M, Reich RM, Wilhelm ME, et al. ChemSusChem. 2016;9:1773-1776.

10. Kumar V, Talisman IJ, Bukhari O, Razzaghy J, Malhorta SV. RSC Adv. 2011;1:1721-1727.

11. Sanhueza CA, Mayato C, Machin RP, Padron JM, Dorta RL, Vazquez JT. Bioorg Med Chem Lett. 2007;17:3676-3681.

12. Shaffer KJ, Taylor CM. Org Lett. 2006;8:3959-3962.

13. Kim J-Y, Di Bussolo V, Gin DY. Org Lett. 2001;3:303-306.

14. (a) Lafuente L, Díaz G, Bravo R, Ponzinibbio A. Lett Org Chem. 2016;13 (3):195-200;

(b) Díaz G, Ponzinibbio A, Bravo RD. Carbohydr Res. 2014;393:23-25;

(c) Díaz G, Ponzinibbio A, Bravo RD. Top Catal. 2012;55:644-648;

(d) Tasca JE, Ponzinibbio A, Diaz G, Bravo RD, Lavat A, González MG. Top Catal. 2010;53:1087-1090;

(e) Ponzinibbio A, Colinas PA, Lieberknecht A, Bravo RD. Lett Org Chem. 2006;3 (6):459-462;

(f) Colinas PA, Ponzinibbio A, Lieberknecht A, Bravo RD. Tetrahedron Lett. 2003;44(43):7985-7988.

15. -dodecyl-3-methylimidazolium tetrafluoroborate. Anhydrous sodium tetrafluoroborate $(15.30 \mathrm{~g}, 0.14 \mathrm{~mol}), 1$-methylimidazole $(11.5 \mathrm{ml}, 0.14 \mathrm{~mol})$ and 1-bromododecane $(33.55 \mathrm{ml}, 0.14 \mathrm{~mol})$ were placed in a round bottom flask equipped with a reflux condenser. The mixture was stirred at $80^{\circ} \mathrm{C}$ for 4 hs, under inert atmosphere. The resultant suspension was diluted with $25.0 \mathrm{ml}$ of acetonitrile and then filtered. After the solvent was removed under reduce pressure, the ionic liquid was dried at $80^{\circ} \mathrm{C}$ in vacuo $(0,02$ torr) for 6 hs to obtained a light yellow semi-solid product (yield $=97 \%$ ). $1 \mathrm{H} \mathrm{NMR}(500 \mathrm{MHz}$, $\mathrm{CDCl} 3): \delta 8.97(\mathrm{~s}, 1 \mathrm{H}, \mathrm{H}-2), 7.42(\mathrm{~s}, 1 \mathrm{H}, \mathrm{H}-4), 7.34(\mathrm{~s}, 1 \mathrm{H}, \mathrm{H}-3), 4.14(\mathrm{t}, \mathrm{J}=7.78$ $\mathrm{Hz}, 2 \mathrm{H}, \mathrm{H}-5), 3.91$ (s, $3 \mathrm{H}, \mathrm{H}-1$ ), 1.81 (broad t, $2 \mathrm{H}, \mathrm{H}-6), 1.25-1.18$ (m, $18 \mathrm{H}, \mathrm{H} 7-$ 15), 0.81 (t, J= $7.28 \mathrm{~Hz}, 3 \mathrm{H}, \mathrm{H}-16) .13 \mathrm{C} \mathrm{NMR}(125 \mathrm{MHz}, \mathrm{CDCl} 3): \delta 136.20$ (C2), 123.79 (C3), 122.13 (C4), 49.96 (C5), 36.22 (C1), 31.83 (C6), 30.07, 29.55, 29.53. 29.47, 29.34, 29.26, 28.93, 26.16, 22.60 (C7-C15), 14.04 (C16).
16. Ionic liquid ( $10 \% \mathrm{mmol}$ ) and 3,4,6-tri-O-benzyl-D-glucal (200 $\mathrm{mg}, 0.48 \mathrm{mmol}$ ) were placed in a round-bottomed flask and dissolved in $2.0 \mathrm{ml}$ of dichloromethane, then were added acetone $(0.8 \mathrm{ml})$ and saturated $\mathrm{NaHCO}_{3}$ aqueous solution $(1.5 \mathrm{ml})$. To this vigorously stirred biphasic mixture was added dropwise a solution of oxone $(600 \mathrm{mg}, 0.9760 \mathrm{mmol}$ in $2.5 \mathrm{ml}$ of water) at $0^{\circ} \mathrm{C}$ for 15 minutes, maintaining the temperature 20 minutes more. After completion of the reaction, the mixture was extracted with dichloromethane (5 $\mathrm{x} 2.0 \mathrm{ml}$ ) and the combined organic phases were dried over sodium sulphate (Na2SO4). After filtration, the solvent was evaporated and the residue was immediately dissolved in anhydrous methanol $(5.0 \mathrm{ml})$ and stirred for $12 \mathrm{hs}$ at room temperature. This solution was concentrated under reduced pressure and the residue was purified by column chromatography to obtain pure methyl 3,4,6-tri-O-benzyl- $\beta$-D-glucopyranoside. $1 \mathrm{H}$ NMR (300 MHz, CCl3D): $\delta 7.38$ $7.15(\mathrm{~m}, 15 \mathrm{H}, 3 \mathrm{C} 6 \mathrm{H} 5), 4.94-4.81$ y $4.64-4.52(\mathrm{~m}, 6 \mathrm{H}, \mathrm{CH} 2 \mathrm{Ph}), 4.19$ y 4.16 (d, 1 H, J=7.26 Hz, H-1), 3.74 (m, 2 H, H-6), 3.60-3.58 (m, 3 H, H-3, H-4, H-5), 3.55 (s, $3 \mathrm{H}, \mathrm{OCH} 3$ ), 3.53 (broad s, $1 \mathrm{H}, \mathrm{H}-2$ ) , 2.46 (broad s, $1 \mathrm{H}, \mathrm{OH}) .13 \mathrm{C}$ NMR $(75 \mathrm{MHz}$, CCl3D): $\delta 138.65,138.16,138.11,128.56-128.27,127.99-127.61$ (3 C6H5) 103.74 (C1), 84.54 (C3), 77.68 (C4), 75.22 (C10), 75.17 (C9), 75.03 (C8), 74.66 (C2), 73.56 (C5), 68.90 (C6); 57.17 (C22)

17. Rani S, Vankar YD. Tetrahedron Lett. 2003:44:907.

18. Ionic liquid $(10 \% \mathrm{mmol})$ and 3,4,6-tri-O-benzyl-D-glucal (200 $\mathrm{mg}, 0.48 \mathrm{mmol})$ were placed in a round-bottomed flask and dissolved in $2.0 \mathrm{ml}$ of dichloromethane, then were added acetone $(0.8 \mathrm{ml})$ and saturated NaHCO3 aqueous solution $(1.5 \mathrm{ml})$. To this vigorously stirred biphasic mixture was added dropwise a solution of oxone $(600 \mathrm{mg}, 0.9760 \mathrm{mmol}$ in $2.5 \mathrm{ml}$ of water) at $0^{\circ} \mathrm{C}$ for 15 minutes, maintaining this temperature 20 minutes more. The reaction was controlled by TLC, until no further progress was observed. The mixture was extracted with dichloromethane $(5 \times 2.0 \mathrm{ml})$ and the combined organic phases were dried over sodium sulphate (Na2SO4). This solution was concentrated under reduced pressure and the residue was purified by column chromatography. 1H NMR (500 MHz, CCl3D): $\delta$ 7.43-7.27 (m, 15 H, 3 C6H5), 5.43 (d, $1 \mathrm{H}, \mathrm{J}=3.16 \mathrm{~Hz}, \mathrm{H}-1), 4.92-4.73(\mathrm{~m}, 1 \mathrm{H}, \mathrm{H}-2), 4.66-4.43(\mathrm{~m}, 6 \mathrm{H}, \mathrm{CH} 2 \mathrm{Ph})$ 4.30 (d, 1H, J=7.55 Hz, H-C5), 4.01 (d, 1H, H-4), 3.59-3.47 (m, 2 H, H-C6), 1.86 and 1.38 ( $\mathrm{m}, 2 \mathrm{H}, \mathrm{OH} \mathrm{C2}$ and $\mathrm{C} 3$ ). 13C NMR (125 MHz, CCl3D): $\delta$ 138.15-136.01, 128.50-127.94 (C6H5), 93.38 (C1), 82.73 (C4), 78.39 (C3), 75.22 (C2), 74.87$73.58(\mathrm{CH} 2 \mathrm{Ph}), 73.23$ (C5), 69.21 (C6). Minor $\beta$ anomer: $\delta 4.82$ and $97.39(\mathrm{H}-1$ and $\mathrm{C} 1)$.

19. H NMR (600 MHz, CCl3D): $\delta 7.42-7.18$ (m, 15 H, 3 C6H5), 5.00 (d, $1 \mathrm{H}, 11.37 \mathrm{~Hz}$ $\mathrm{H}-5), 4.88-4.53$ (m, $6 \mathrm{H}, \mathrm{CH} 2 \mathrm{Ph}$ ), 3.90 (d, $1 \mathrm{H}, \mathrm{J}=8.83 \mathrm{~Hz}, \mathrm{H}-1)$ ) 3.73-3.71 (dd, $1 \mathrm{H}$, $\mathrm{H}-6)$, 3.66-3.53 (m, $5 \mathrm{H}, \mathrm{H}-3, \mathrm{H}-4, \mathrm{H}-6$ and $\mathrm{CH} 2 \mathrm{OH}), 3.38-3.35(\mathrm{t}, 1 \mathrm{H}, 8.91 \mathrm{~Hz}$ H-2), 3.03-3.00 (m, $2 \mathrm{H}, \mathrm{CH} 2 \mathrm{~N}$ ). 13C NMR (150 MHz, CCl3D): $\delta 138.71,138.08$, 137.86, 128.61-127.72 (C6H5), 90.91 (C1), 85.54 (C3), 77.67 (C4), 75.87 (C5), 75.09 (C2), 75.02, 74.58, $73.52(\mathrm{CH} 2 \mathrm{Ph}), 68.98$ (C6), $62.99(\mathrm{CH} 2 \mathrm{OH}), 49.48$ $(\mathrm{NCH} 2)$. 